Utah State University

DigitalCommons@USU

$1-1-1988$

\title{
Comparison of Simultaneous MST Radar and Electron Density Probe Measurements During STATE
}

\author{
J. C. Ulwick \\ K. D. Baker \\ M. C. Kelley \\ B. B. Balsley \\ W. L. Ecklund
}

Follow this and additional works at: https://digitalcommons.usu.edu/sdl_pubs

\section{Recommended Citation}

Ulwick, J. C.; Baker, K. D.; Kelley, M. C.; Balsley, B. B.; and Ecklund, W. L., "Comparison of Simultaneous MST Radar and Electron Density Probe Measurements During STATE" (1988). Space Dynamics Lab Publications. Paper 133.

https://digitalcommons.usu.edu/sdl_pubs/133

This Article is brought to you for free and open access by the Space Dynamics Lab at DigitalCommons@USU. It has been accepted for inclusion in Space Dynamics Lab Publications by an authorized administrator of DigitalCommons@USU. For more information, please contact digitalcommons@usu.edu.

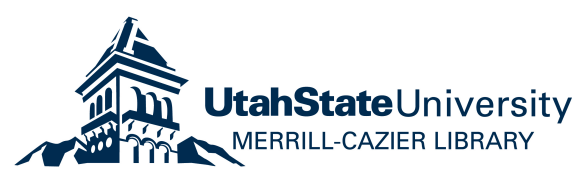




\title{
Comparison of Simultaneous MST Radar and Electron Density Probe Measurements During STATE
}

\author{
J. C. Ulwick and K. D. Baker \\ Department of Electrical Engineering, Utah State University, Logan \\ M. C. Kelley \\ School of Electrical Engineering, Cornell University, Ithaca, New York
}

B. B. Balsley AND W. L. Ecklund

Aeronomy Laboratory, National Oceanic and Atmospheric Administration, Boulder, Colorado

\begin{abstract}
During the Structure and Atmospheric Turbulence Environment (STATE) campaign in June 1983, three small rockets (Super Arcas) containing dc probes to measure electron density irregularities with high spatial resolution were launched at Poker Flat, Alaska. The rockets were launched at three different times when the nearby MST (mesospheric, stratospheric, and tropospheric) radar showed intense regions of backseatter in the mesesphere. The first and third flights (STATE 1 and STATE 3) were perfectly successful, providing high-quality electron density measurements; STATE 2 did not produce any useful results. When the electron density measurements are compared with the radar echo power as a function of altitude for STATE 1 and 3, large fluctuations and strong gradients in the electron density profiles are observed in the region of most intense backscatter. The electron density profiles show different characteristics in the peak scattering region with respect to altitude, electron density gradients, and irregularities. Power spectra of the electron density spatial fluctuations were derived from the measured electron densities for the region from approximately 65 to $90 \mathrm{~km}$ for several height intervals, with the smallest being approximately $100 \mathrm{~m}$. In the region of most intense backscatter, the spectral power over the entire frequency range increases by almost 3 orders of magnitude for both rocket data sets. For STATE 1 a linear fit to the $\log -\log$ power spectral plots between $1.0-80 \mathrm{~Hz}$ (i.e., spatial scales from about 500 to $5 \mathrm{~m}$ ) can be approximated by a power law with an index of about $-(5 / 3)$, as would be expected in an inertial subrange of homogeneous, isotropic turbulence. The spectra, moreover, show a continuous steepening of the spectral slope in the viscous subrange at frequencies above $100 \mathrm{~Hz}$ (approximately $4.5-0.5 \mathrm{~m}$ ), giving a much higher spectral index. The STATE 3 spectra, on the other hand, show a steeper spectral index near -2.0 in the inertial subrange bul steepening at the higher frequencies, as do the STATE 1 data. A detaled intercomparison of the probe data is presented, followed by an absolute comparison between the radar and rocket measurements. Reasonable agreement is seen between the observed echo power profile and the profile calculated using the 3-m electron density fluctuations obtained from the rocket data.
\end{abstract}

\section{INTRODUCTION}

The use of coherent backscatter radars has been recognized as an important way to montor atmospheric conditions. In the troposphere and lower stratosphere, the radar backscatter signal depends upon aerosols and water vapor. In the mesosphere, the radar signature depends upon irregularities in the electron concentration. Major efforts have been made in the Federal Republic of Germany and in the United States to measure the properties of the mesosphere using coherent backscatter radar at VHF wavelengths. Since the Mesospheric, Stratospheric and Tropospheric (MST) radar at Poker Flat Research Range, Alaska (PFRR), is so well situated to allow comparison between rocket-borne sensors and the radar the Structure and Atmospheric Turbulence Environment (STATE) experiment [Philbrick et al., 1984] was conducted there during the first 2 weeks of June 1983. In situ measurements of the atmospheric properties were made to compare to the MST radar signals in an effort to interpret the dynamical conditions in the middle atmosphere. The measurements were

Copyright 1988 by the American Geophysical Union.

Paper number 7D0929.

0148-0227/88/007D-0929\$05.00 made during the summer season at PFRR, based on the large signals which have been measured by the MST radar over the past several years. Rockets with probes which can measure the electron irregularitıes with high spatial resolution were launched on three occasions which corresponded to selected conditions observed in real time in the radar data. In one of these cases, several other instruments were launched to study the structure of the neutral atmosphere. Profiles of density, temperature, wind and turbulence properties were measured. This paper and the three following ones are concerned with the results of the STATE campaign.

In this paper, electron density structure in the cold, polar summer mesosphere is investigated using rocket probes and MST radar data obtained at Poker Flat, Alaska, during STATE. The observed structure is believed to be the result of turbulence in the neutral atmosphere. A companion paper by Kelley and Ulwick [this issue], uses the rocket probe data to further investigate mesospheric structure and turbulence, a paper by Watkins et al. [this issue] utilizes the MST radar data to investigate turbulent energy dissipation rates and inner scale sizes, and a paper by Fritts et al. [this issue] examines the structure and characteristics of the gravity field.

As part of the STATE campaign, in situ high-resolution electron density probe measurements were made by rocket- 

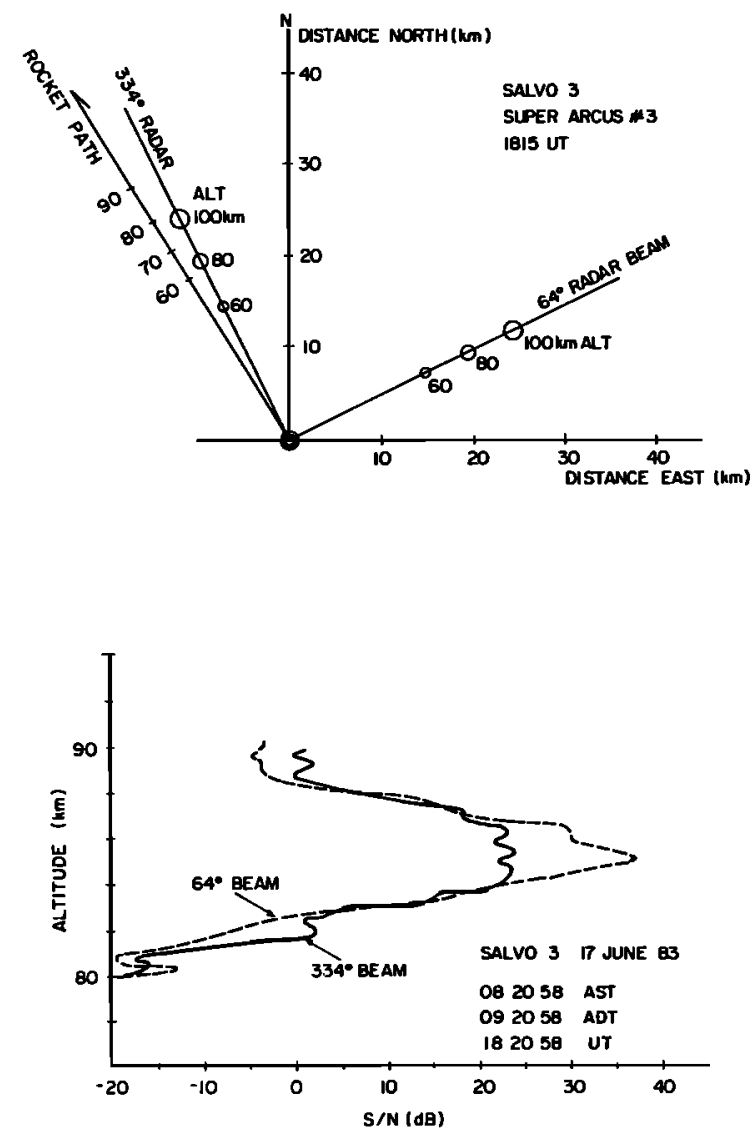
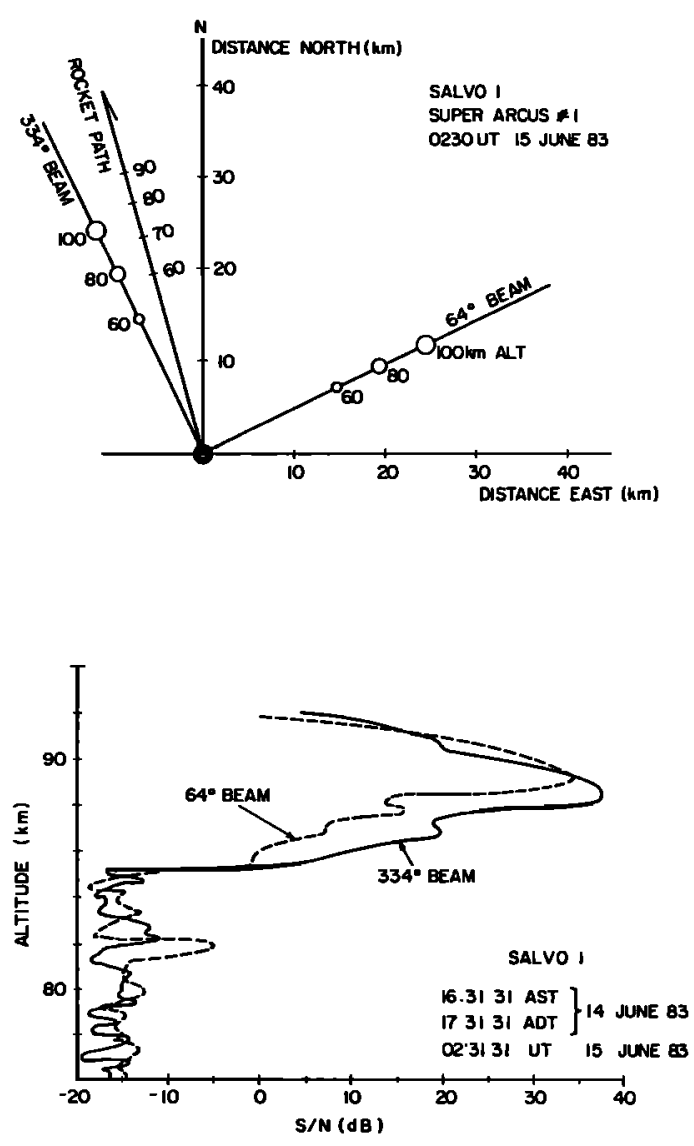

Fig. 1. Poker Flat MST radar returns during the STATE rocket fights: salvo 1 (lower right panel) and salvo 3 (lower left panel). The upper panels show the radar beam azimuths and the rocket flight path for each case. The open circles on the radar beam line indicate the position and size of the radar scattering area, corresponding to the rocket altitudes. The radar signal-to-noise ratio $(\mathrm{S} / \mathrm{N})$ is in decibels.

borne dc probes on two Super Arcas rockets during salvos 1 and 3. The vertical spatial structure of mesospheric electron density fluctuations were obtained with spatial resolution down to about $10 \mathrm{~cm}$. At mesospheric altitudes it is assumed that the motion of the electrons and ions is controlled by that of the neutral gas, owing to the high collisional frequency. The fluctuations in the profile can thus be used to derive the spectral scales of the turbulent motion [Thrane and Grandel, [1981]. Moreover, the electron density fluctuations should be directly related to the MST radar backscatter measurements, provided that the scattering arises solely from turbulent processes [Balsley and Gage, 1980]. In situ probe measurements are capable of measuring the overall spatial spectrum of the turbulent structure, while the radar is only sensitive to scales of one-half the wavelength of the electromagnetic wave, i.e., about $3 \mathrm{~m}$. The electron density results from rocket salvos 1 and 3 and the corresponding MST radar measurements are the subjects of this paper.

The rocket probes consisted of simple dc probes (Langmuir type) flown on Super Arcas meteorological type rockets from the Poker Flat Research Range in Alaska during mid-June of 1983. The rockets achieved altitudes of about $100 \mathrm{~km}$ along azimuths near the "north" beam of the MST radar, also located at Poker Flat. The relative electron density was measured by monitoring dc electron current to the isolated tip (4.4-cm. length) of the nose cone, which was held at a fixed $+3-\mathrm{V}$ bias potential with respect to the rocket skin. The paint was removed from the rocket motors in order to provide a large area for the return positive ion current. The signals from the dc probe and a spin magnetometer were transmitted in a digital PCM format that used 16 bits per word and 16 words per frame, with a total rate of 8000 words $s^{-1}$. Thus the dc probe provided very high resolution measurements of the electron current, which is presumed to be approximately proportional to the electron density. Since no absolute electron density measurements were made on these payloads, a conversion factor was required to convert the magnitudes of the electron current to electron density values. A more recent Super Arcas rocket was flown that contained a dc probe identical to the STATE probes but additionally included an RF admittance probe for measurement of absolute electron densities. Since this rocket was geometrically and operationally identical to the STATE rockets and flew under similar conditions, i.e., at Poker Flat in the summer with similar solar zenith angle, we used these results to calibrate the STATE probes to obtain electron density values from the measured probe currents.

The Poker Flat 50-MHz MST radar consists of a large dipole antenna array driven by distributed transmitter modules [Balsley et al., 1980]. The three fixed antenna beams were directed (1) in the vertical, (2) $15^{\circ}$ off zenith on azimuth $64^{\circ}$ geographic, and (3) $15^{\circ}$ off vertical on azimith $334^{\circ}$ geographic. Figure 1 shows the flight paths for the STATE 1 and 3 rockets relative to the antenna beam directions. Rocket posi- 

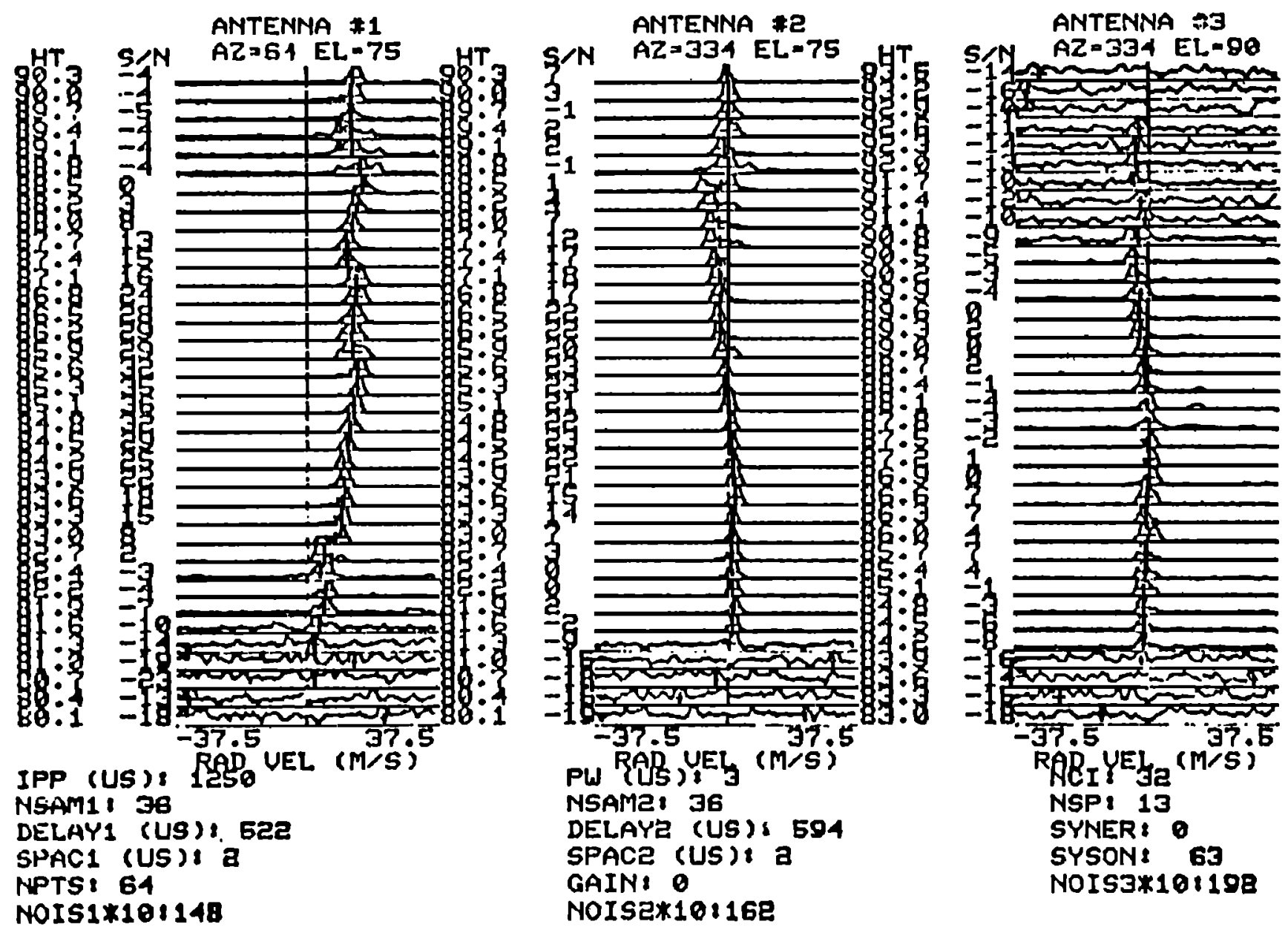

F1g. 2. Sample of the real-time display from the MST radar during the STATE Campaign. The radar signal-to-noise ratio $(S / N)$ in decibels is plotled versus the indicated plasma radial velocity in meters per second for each of the three radar beams at various altitudes.

tion relative to the antenna beams for altitudes $60,70,80$, and $90 \mathrm{~km}$ are shown for both launches. For both oblique beams the positions at the $60-, 80-$, and $100-\mathrm{km}$ regions of backscatter are shown, with the diameter of the circles indicating the approximate areas of backscatter. Figure 1 shows that in both flights the rockets were less than $10 \mathrm{~km}$ away from the regions probed by the radar over the altitudes of prime interest $(80-90 \mathrm{~km})$.

In earlier studies the Poker Flat MST radar has typically been operated with a $15-\mu$ s pulse length in order to cover the tropospheric, stratospheric, and mesospheric scatter regions. This pulse length gives an altitude resolution of $2.2 \mathrm{~km}$. For the STATE campaign, however, the radar data-gathering procedures were modified to allow the radar to accumulate data in 70 range bins on all three directions, where the resolution could be set between $300 \mathrm{~m}(2 \mu \mathrm{s})$ and $2.2 \mathrm{~km}(15 \mu \mathrm{s})$. It was thus possible to record data with $300-\mathrm{m}$ altitude resolution over a continuous mesospheric height range between $70-100$ $\mathrm{km}$. Figure 2 shows a real time Doppler spectra recorded for each of the three antennas during a period of intense echo returns during the STATE campaign. This real-time capability of displaying the returned signals allowed optimization of the launch time of the rockets.

In the next section we describe the data analysis methods employed on the probe results in some detail and then give the results from the STATE 1 and STATE 3 rocket flights. A detailed intercomparison of the probe data is presented, followed by a comparison between the radar and rocket measurements. In a companion paper [Kelley and Ulwick, this issue] some additional implications of the joint data set are further discussed.

\section{Data Presentation}

\subsection{Overview}

The first rocket (STATE 1) was launched on June 15, 1983, at 0230 UT (1730 ADT) and the STATE 3 rocket was launched June 17, 1983, at 1820:58 UT, during periods of strong echo returns. The rockets reached peak altitudes near $100 \mathrm{~km}$, with the rocket velocity changing from about $800 \mathrm{~m}$ $\mathrm{s}^{-1}$ at $70 \mathrm{~km}$ to about $450 \mathrm{~m} \mathrm{~s}^{-1}$ at $90 \mathrm{~km}$. With a sampling rate of about $8000 \mathrm{~Hz}$, this means that the spatial distance between sampling points changed from about 0.1 to $0.05 \mathrm{~m}$ over this height interval. Thus the spatial structure in the electron density could be determined well below the 3-m scale to which the radar is sensitive. Figure 3 shows the height profiles of the electron density (lower scale) and the MST radar echo signal-to-noise ratio ( $\mathrm{S} / \mathrm{N}$ ) in decibels (upper scale) for both flights. It is obvious that in general, the large changes and strong gradients in electron density occurred in the re- 

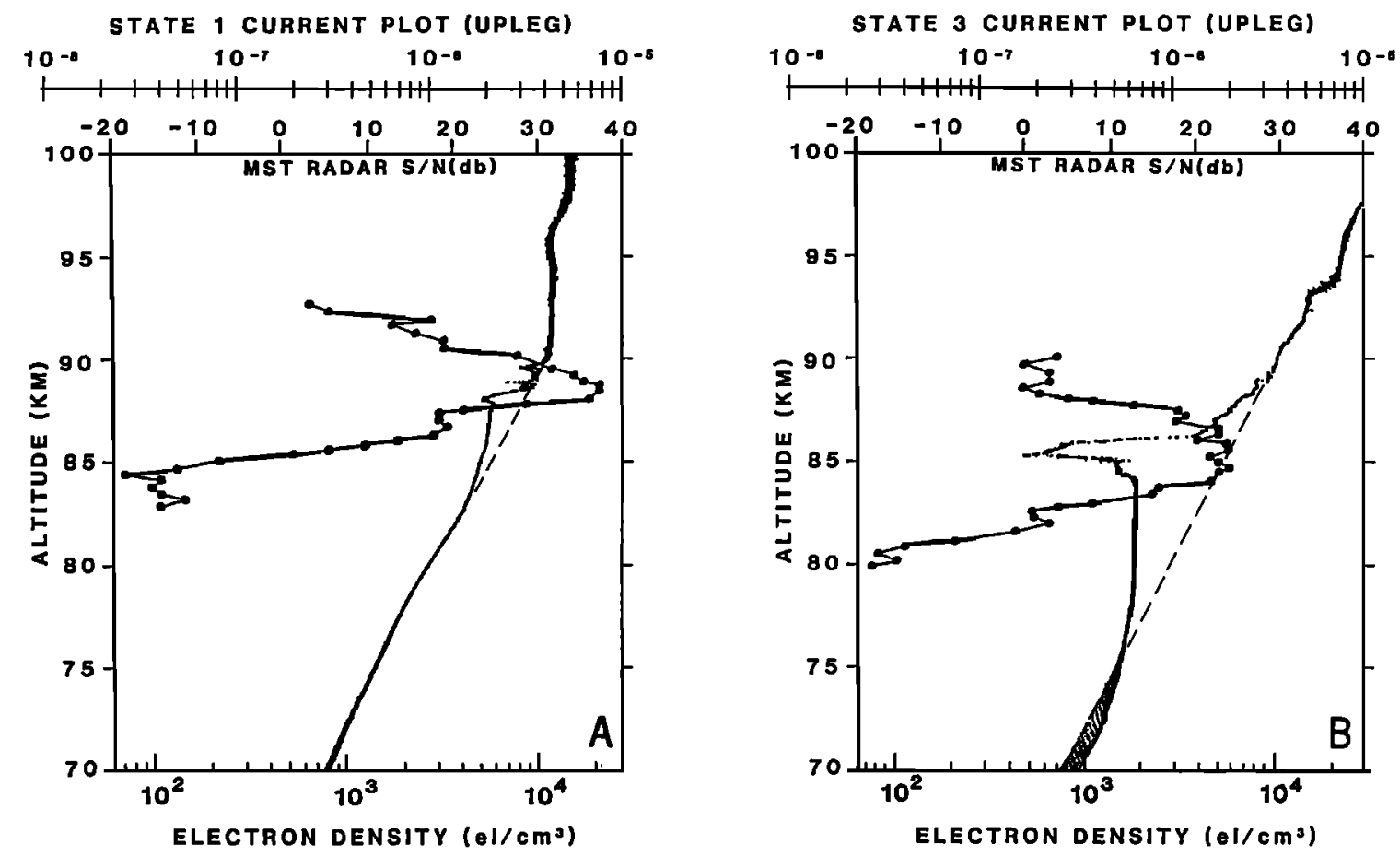

Fig. 3. Height profiles of the rocketborne dc probe results and MST radar echo S/N (solid circles) for the (a) STATE 1 and (b) STATE 3 rocket flights. The dc probe results are given both in (top scale) probe current and (bottom scale) tentative electron density values, assuming a constant proportionality between the two (see text). The dashed lines illustrate a more typical $D$ region profile.

gions of most intense radar backscatter. It should be noted that the STATE $1 \mathrm{~S} / \mathrm{N}$ peak in the radar data is about $37 \mathrm{~dB}$ near $88 \mathrm{~km}$, whereas the STATE $3 \mathrm{~S} / \mathrm{N}$ is much weaker and lower, reaching a peak of only $23 \mathrm{~dB}$ near $85 \mathrm{~km}$. The STATE 3 results suggest that the region of radar backscatter corresponds to the altitude of steep gradients in the electron density caused by a deep "bite-out" in the electron density of almost an order of magnitude at $86 \mathrm{~km}$. For STATE 1, however, the rapidly changing structure in the electron density and the corresponding sharp rise in the radar return power occur above the small depletion (about 10\%) in the electron density profile near $88 \mathrm{~km}$. Note that both electron density profiles are not typical of the normal $D$ region. The STATE 3 profile is particularly atypical in that the vertical electron density gradient is almost zero from 77 to $84 \mathrm{~km}$. (The dashed lines in Figures $3 a$ and $3 b$ emphasize this).

A power spectral analysis of the probe data was performed following the method of Blackman and Tukey [1958]. Spatial power spectra of the relative electron density fluctuations were first calculated from 2048 data points, corresponding to a time series of about $0.25 \mathrm{~s}$ to a height resolution better than $150 \mathrm{~m}$ in the altitudes of prime interest. This time series allowed the data to be spectrally analyzed in a frequency range extending to over $4000 \mathrm{~Hz}$ (i.e., a spatial resolution corresponding to scale sizes of about $12 \mathrm{~cm}$ ). This resolution is considerably finer than the $3-\mathrm{m}$ structure to which the $50-\mathrm{MHz}$ radar is sensitive. In addition, longer time series were analyzed, using 2048 data points over $0.5-, 1.0-, 2.0-, 4.0-$, and $8.0-\mathrm{s}$ intervals, to examine the spectra at the lower frequencies (longer scale sizes). During these measurements the rocket spin rate was near 22 revolutions $s^{-1}$. Under these conditions, even tipmounted probes suffer from some contamination at the spin frequency which is visible in the power spectra, if the data are treated as is usually done by constructing deviations from a running mean. Since the spin effects were so prominent in the data, an attempt was made to remove these as much as possible by detrending the data, using a 12-term polynomial fit to the data. Power spectral analysis was conducted on both rocket data sets, and these will be discussed individually in the following paragraphs and then compared both with the radar data and with each other.

\subsection{STATE I}

Inspection of the STATE 1 electron density results and the radar data in Figure 3 suggests that the power spectral analysis should be done in two time/altitude intervals: (1) from 95 to $111 \mathrm{~s}(76-85.8 \mathrm{~km})$, where there were no strong radar echoes, and (2) from 111 to $123 \mathrm{~s}(85.5-92 \mathrm{~km})$, where there were significant radar echoes.

2.2.1. Interval from $95-111 \mathrm{~s}(76-85.8 \mathrm{~km})$. These data were spectrally analyzed in two time intervals, as shown in Figure $4 a$. No turbulent structure is apparent in the electron current measurements shown in interval 1 , which is dominated by rocket spin effects. The power spectrum of these data, shown in Figure $4 b$, shows the only significant spectral component to be at the spin frequency (approximately $22 \mathrm{~Hz}$ ). Interval 2 of Figure $4 a$ exhibits more structure in the current data, and the corresponding spectrum in Figure $4 c$ shows a distinct increase in fluctuation power at frequencies below 100 $\mathrm{Hz}$. It should be noted in Figure $4 c$ that the noise level at high frequencies decreased with increasing altitude compared with Figure $4 b$, an effect which was also observed by Royrvik and Smith [1984] in their investigation of mesospheric turbulence in Peru.

In power spectral analysis it is sometimes useful to fit a power law to the spectrum to determine the spectral index $n$, 

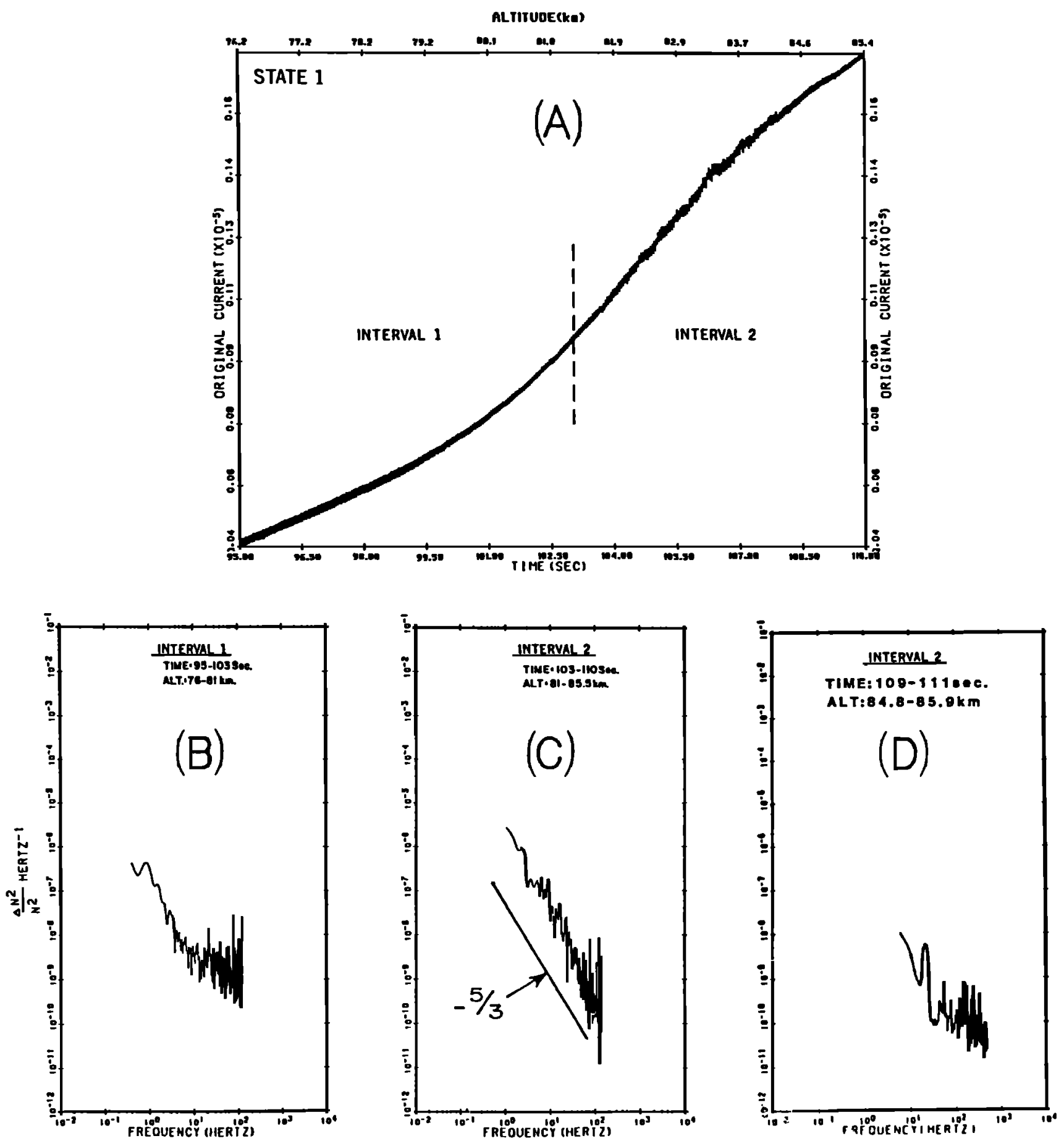

Fig. 4. The dc probe results for the STATE 1 rocket: $(a)$ probe current versus time; $(b)$ interval $1,95-100 \mathrm{~s}$; and $(c)$ interval 2,103-110 s; and $(d)$ interval $2,109-111 \mathrm{~s}$, the power spectral analysis of the fluctuations.

using the relationship $P(\omega) \propto \omega^{n}$. For a probe traveling at a high velocity, $V_{R}$, with respect to the irregularities, this is equivalent to a one-dimensional spectrum $S(k) \propto k^{n}$, where $k=\omega / V_{\mathbf{R}}=2 \pi / \lambda$. The spectral index for Figure $4 c$ between 1 and $100 \mathrm{~Hz}$ was found to be about -1.7 ; a value reasonably close to the $-(5 / 3)$ value predicted by turbulent theory for a one-dimensional spectrum of density fluctuations in an inertial subrange of homogeneous, isotropic turbulence [Tartarskii, 1961]. With a rocket velocity of about $500 \mathrm{~m} \mathrm{~s}^{-1}$ in this time interval, Figure $4 c$ suggests that the inertial subrange of turbu- lence extends at least over the range from 500 down to about $10 \mathrm{~m}$ (where the slope breaks).

Since the current probe signal is rather weak in this height interval, we cannot resolve the $165-\mathrm{Hz}$ portion of the spectrum (i.e., the frequency corresponding to the 3-m structure responsible for the radar echoes) as was done in subsequent time intervals. However, we certainly can say that the fluctuations were stronger in the $81-$ to $85-\mathrm{km}$ range than in the $76-$ to $81-\mathrm{km}$ range, based on the results shown in Figures $4 b$ and $4 c$. This increase in fluctuation strength agrees with the radar 

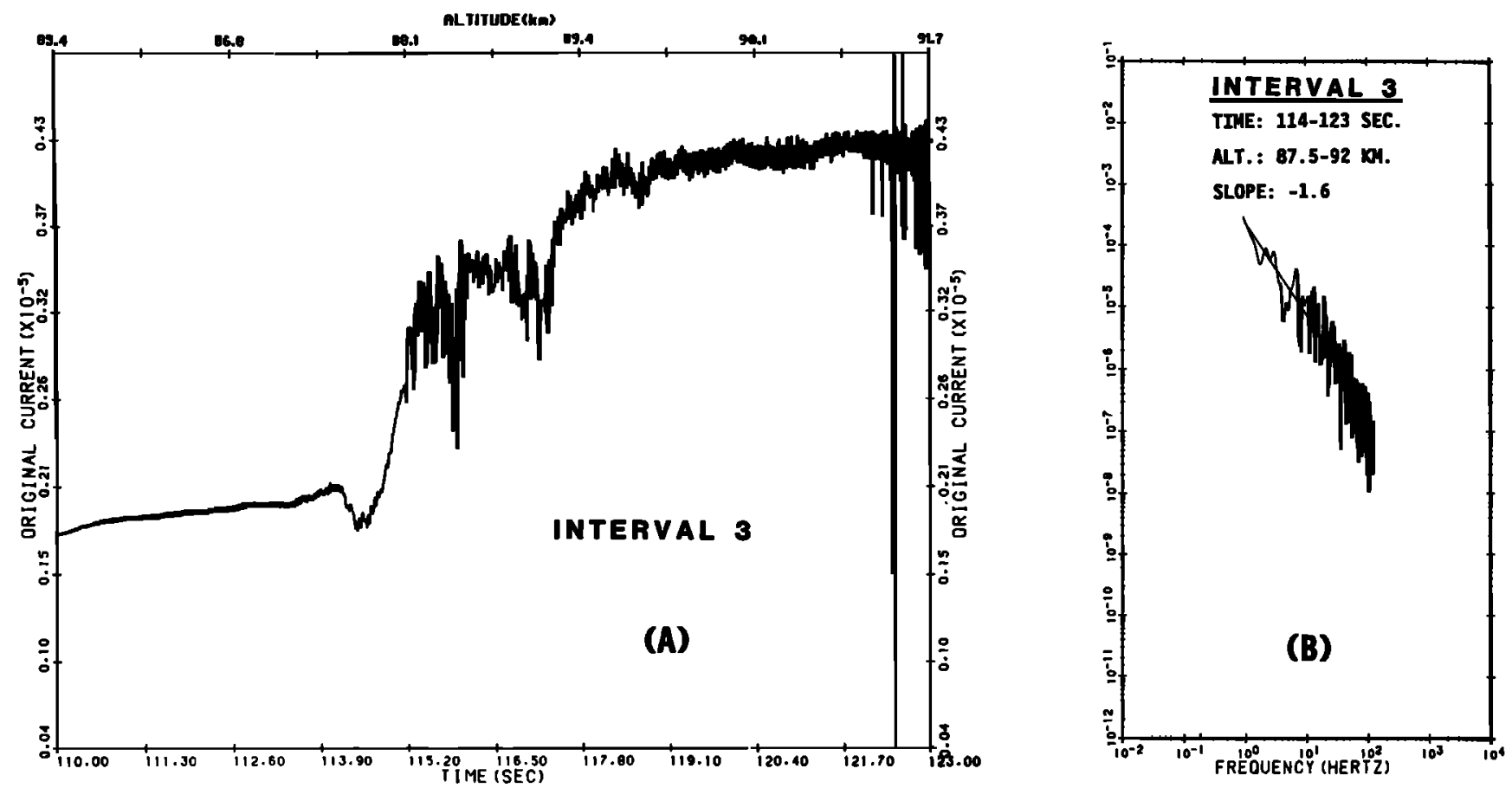

Fig. 5. (a) Profile shows the electron current and defines interval 3. (b) The power spectrum of the electron density fluctuations in the last $9 \mathrm{~s}$ of interval 3.

data, which also show an increase in signal power at $83 \mathrm{~km}$ relative to echoes below about $82.5 \mathrm{~km}$ (which were not detectable) and at the higher altitude at $84.5 \mathrm{~km}$, as shown in Figure 3. To further study this weak relative maximum in the radar echoing power, we have concentrated on the 2-s interval from 109 to $111 \mathrm{~s}$ and plotted its power spectrum in Figure $4 d$. Indeed, the fluctuation signal is very weak over the whole frequency range, with the spike at the spin frequency of $22 \mathrm{~Hz}$ dominant. There is also a minimum in radar $\mathrm{S} / \mathrm{N}$ near 84.5 $\mathrm{km}$, as shown in Figure 3. Thus the rocket data are in reasonable agreement with the radar echo power over the height range from 81 to $84.5 \mathrm{~km}$, even in this region of very weak radar signal ( $-10-\mathrm{dB} \mathrm{S/N}$ for the radar data).

2.2.2. Interval from $111-123 \mathrm{~s}(85.5-92 \mathrm{~km})$. The probe current collected during the 110- to 123-s time interval is shown in Figure $5 a$, using a current scale about one-third that in Figure 4 because of the much larger variations in the current over this height interval. The spectra from 110 to $114 \mathrm{~s}$ (not shown) are very similar to those of Figure $4 c$, i.e., the signal is rather weak at the $3-\mathrm{m}$ wavelength of the radar but shows a distinct power increase at frequencies below $100 \mathrm{~Hz}$. Analysis of the data between 111-123 s at 0.5-s intervals (to be discussed later) shows that significant power increases at frequencies corresponding to $3-\mathrm{m}$ wavelengths began at a rocket altitude of $86.6 \mathrm{~km}$. The MST radar showed a rapid increase in the echo return power, beginning at about $84.7 \mathrm{~km}$ (about $-15 \mathrm{~dB} \mathrm{~S} / \mathrm{N}$ ) and increasing to a value near $17 \mathrm{~dB}$ at $86.6 \mathrm{~km}$, where the rocket probe data at $3 \mathrm{~m}$ shows significant power increases. Thus it is obvious that the MST radar exhibits much more sensitivity to the 3-m structure than does the probe data. Still, it is very encouraging that both techniques detect the two regions with turbulent structure $(81-84.5 \mathrm{~km}$ and above $86.6 \mathrm{~km}$ ) and the region of little or no detectable turbulence separating them. Detailed comparison of the rocket and radar results is presented in section 3.2 of this paper.
To study the region from 114 to $123 \mathrm{~s}$ (Figure 5a), we first analyze the whole interval, as shown in the spectrum in Figure $5 b$. Comparing Figure $5 b$ with Figures $4 c$ and $4 d$, the fluctuation power is higher by $2-4$ orders of magnitude. This very strong signal allows us to perform a detailed study of the spectra in this height range. Two aspects are immediately clear: at the lower frequencies (small $k$ values), the spectral index is near -1.6 ; however, as $k$ increases, the spectrum becomes much steeper. These characteristics are exactly as one would predict for a passive scalar mixed by a turbulent neutral fluid, since theory for such a process predicts that the one dimensional spectrum of a passive scalar should display a $-(5 / 3)$ slope in the inertial subrange, with a break to a steep slope occurring at some large value of $k$ [Driscoll and Kennedy, 1985]. A detailed discussion of the mixing physics as implied by the present data set is reserved for a companion paper [Kelley and Ulwick, this issue].

To examine the spectral characteristics in more detail, the data from 115 to $123 \mathrm{~s}$ were analyzed over four 2-s intervals. The spectra in Figure 6 clearly change from forms characteristic of mesospheric turbulence (Figures $6 a$ and $6 b$ ), to the "white noise" power spectrum in Figure $6 d$, which is almost certainly due to plasma instabilities in the lower $E$ region [Fejer and Kelley, 1980]. It is well known that such structures do not scatter $50-\mathrm{MHz}$ radar signals transmitted at high elevations in the polar regions, since the plasma waves are such that $k * B=0$, i.e., they produce highly anisotropic scattering with a maximum scattering cross section perpendicular to the Earth's magnetic field. The steep spectral index for higher frequencies is clearly shown in Figures $6 a$ and $6 b$. In Figure $6 a$ the power law spectral index of -1.6 from the results of Figure $5 b$ has been superimposed on the spectrum. In the higher frequency range, a power law with index -7.0 is also shown.

Figure 7 shows a composite power spectrum covering the 

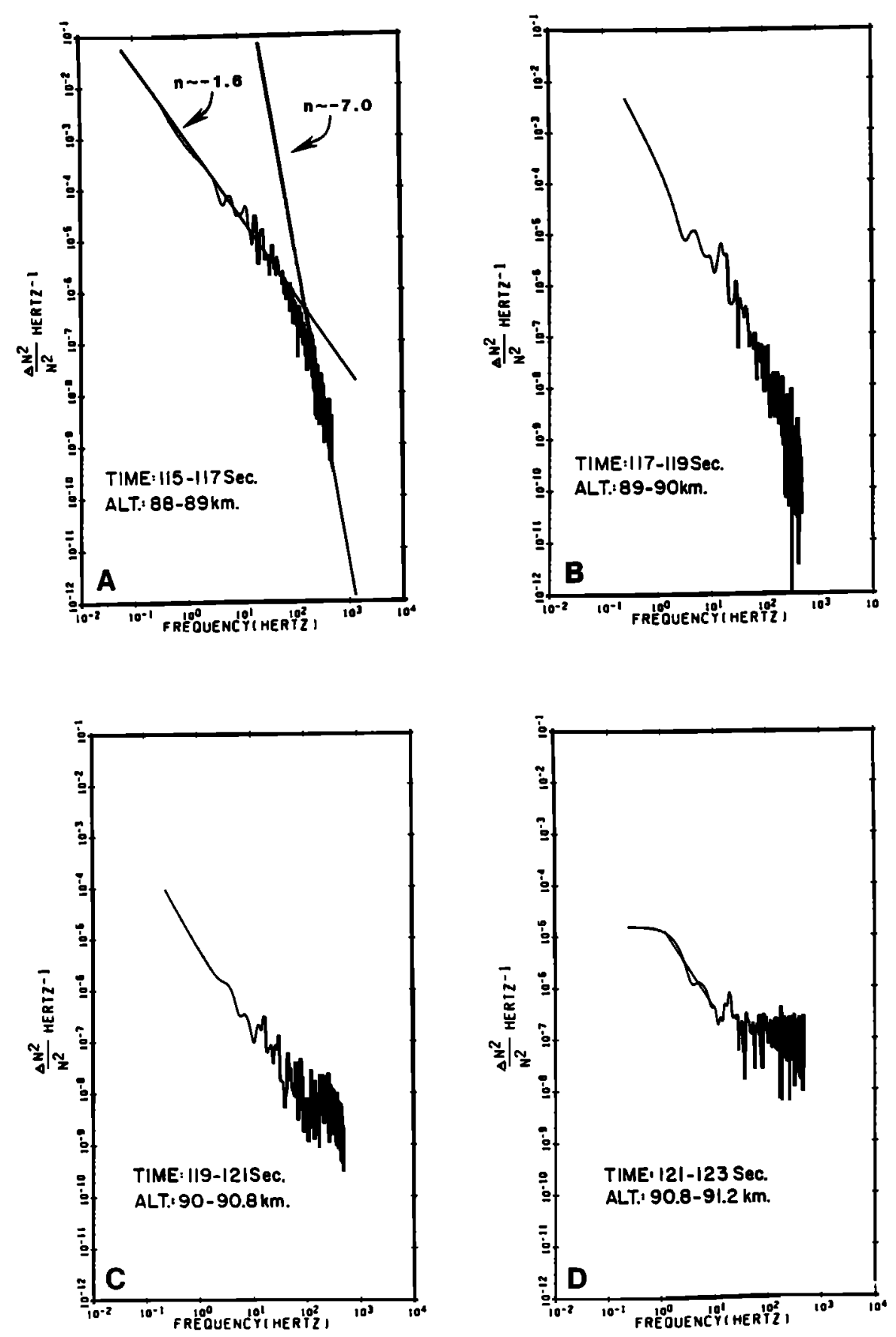

Fig. 6. STATE 1 electron density power spectral analysis results for 2-s intervals between 115 and $123 \mathrm{~s}$ : (a) $115-117 \mathrm{~s}$;

(b) 117-119 s; (c) 119-121 s; and (d) 121-123 s.

time period from 114 to $118 \mathrm{~s}$ (the region showing the largest current fluctuations). For the lower frequencies between 1 and $100 \mathrm{~Hz}$ (corresponding to wavelengths of about $550-5.5 \mathrm{~m}$ ), the entire time period was used. At the higher frequencies between 10 and $1000 \mathrm{~Hz}$ (corresponding to wavelengths of 55 to $0.5 \mathrm{~m}$ ), the spectrum was obtained by averaging all 0.25 -s spectra in the time interval $114-118 \mathrm{~s}$. The two plots are superimposed and overlaid in the $10-$ to $100-\mathrm{Hz}$ range. Additional scales of wavelength (in meters), $[\Delta N / N]^{2} / \mathrm{Hz}^{-1}$, and wave number (in radians per meter) are also included in the plot. Spectral indications of $-1.6,-3.0$, and -7.0 are shown to compare with the composite spectrum. Also shown is the 3-m MST radar operating frequency (about $165 \mathrm{~Hz}$ ). The rise in power at $10 \mathrm{~Hz}$ is caused by an interference due to an on-board magnetometer and should be ignored.

\subsection{STATE 3}

The electron density profile for STATE 3 shown in Figure 3 was analyzed in two intervals: from 100 to $110 \mathrm{~s}(62.8-82.9$ $\mathrm{km})$, and 110 to $120 \mathrm{~s}(82.9-87.8 \mathrm{~km})$, as shown in Figure 8 . The short time interval spectra from 80 to $110 \mathrm{~s}$ were all very similar, with spin effects dominating, as can be seen in Figure $8 a$. Essentially no evidence for turbulence was found in this range. For example, Figure $8 a$ shows the spectrum for 77.2 $82.9 \mathrm{~km}$, which has a strong peak between 20 and $30 \mathrm{~Hz}$. In contrast, the spectrum from 82.9 to $87.8 \mathrm{~km}$ (Figure $8 b$ ) has 


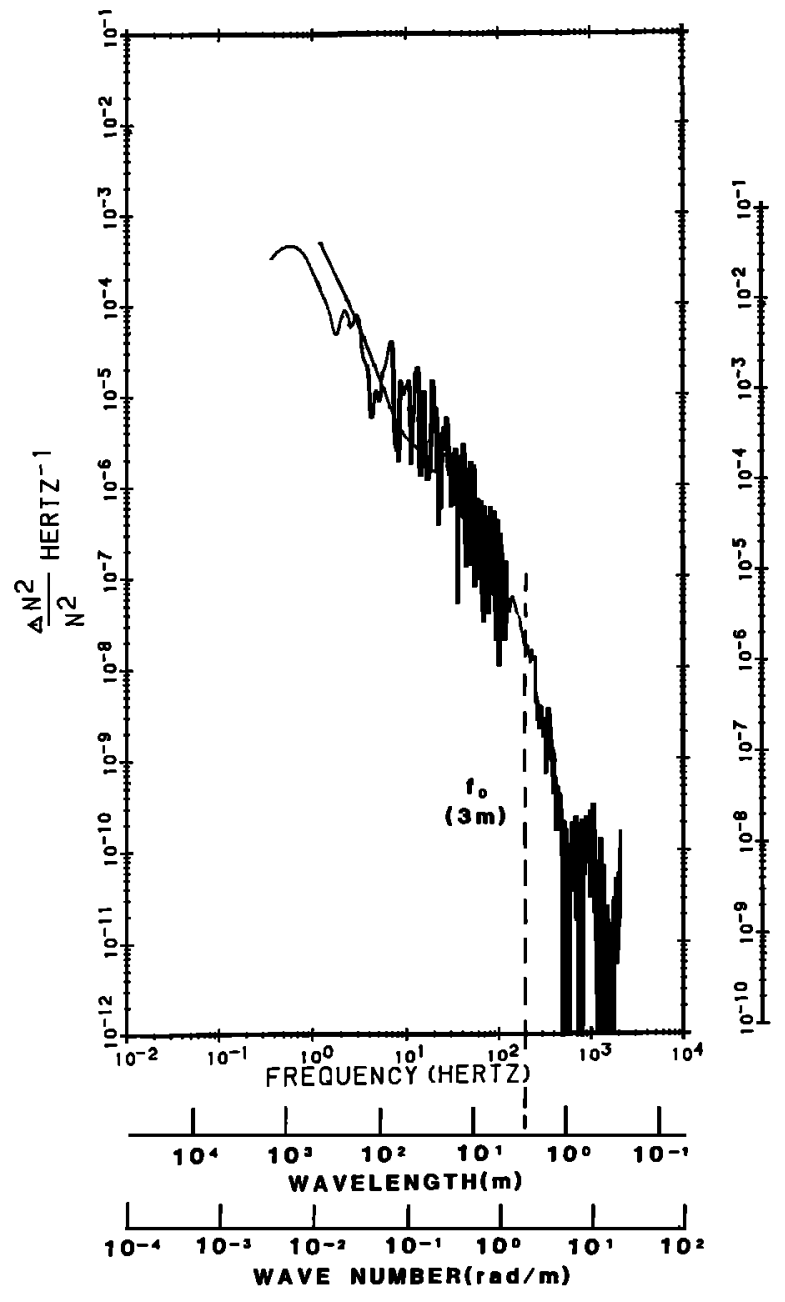

Fig. 7. Composite power spectrum from STATE 1 results for the interval from 114 to $118 \mathrm{~s}$ (see text).

very high power levels. The spectral index of a straight-line fit is about -1.8 from 1.0 to $50 \mathrm{~Hz}$ in Figure $8 b$, and the fluctuation power is up by about 2 orders of magnitude in comparison with the plot in Figure $8 a$ for the same frequency range. As noted earlier, the intense radar backscatter signal is centered in the region of the "bite-out" of the electron density profile, as is the spectrum plotted in Figure $8 b$.

In Figure $9 a$ the averaged spectrum for all 0.5 -s spectra in the 110 - to $120-\mathrm{s}(82.9-87.8 \mathrm{~km})$ interval is superimposed on the spectrum from Figure $8 b$. In Figure $9 b$ the composite spectrum (Figure 7), obtained in the same way as for STATE 1 $(87.5-89.5 \mathrm{~km})$, is repeated for comparison. (The background noise level at high frequencies is near $10^{-10} \mathrm{~Hz}^{-1}$ for both flights).

\section{Discussion}

\subsection{Comparison of STATE 1 and STATE 3 Results}

Although only a few days separated the two rocket flights, the relationship between the electron density profile and the radar scattering profile is quite different for the two measurements. In STATE 3 a broad depletion in electron density seemed to commence at about $75 \mathrm{~km}$. Between 77 and $84 \mathrm{~km}$, instead of the usual monotonic increasing profile, there was almost no vertical density gradient at all. At $85 \mathrm{~km}$ the density abruptly began to decrease, resulting in a net depletion of nearly an order of magnitude when compared with a more normal profile. The radar scattering region was exactly centered on this deep "bite-out" in the electron density. This depletion occurred within the broad temperature minimum (80-92 km), detected on June 15, 1983 (C. R. Philbrick, private communication, 1986). Johannessen and Krankowsky [1972] reported a very similar ionization profile (i.e., a sharp ledge near $85 \mathrm{~km}$, a sharp minimum immediately below the ledge, and a depletion width of about $1 \mathrm{~km}$ ) from a probe on a rocket launched to study the ion composition of the cold summer, northern-latitude mesopause. Although we cannot be entirely sure at this time, we speculate that this region of depeleted electron density is due to the attachment of electrons to hydrated molecules associated with polar mesospheric clouds. The resulting heavy negative ions would not be collected as efficiently by the Langmuir probe, whose response reflects the electron content of the gas.

The resulting sharp gradients in electron density then may be mixed by turbulent atmospheric motion in this mesopause region and may lead to the strong backscatter echoes. This contention is supported by the presentation in Figure 10, where the electron density $\left(N_{e}\right)$ profile is plotted again along with the high-resolution spectral information $\left(\Delta N_{e} / N_{e}\right)^{2} N_{e}{ }^{2}$. For this plot we have integrated the 0.5 -s density fluctuation spectra in the $0.75 k_{0} \leq k<1.25 k_{0}$ range, where $k_{0}$ is the radar scattering wave number. Three defined peaks at about 84.5 , 85.2 , and $86.1 \mathrm{~km}$ are identified by arrows as 1,2 , and 3 . These peaks are coaligned, with clearly visible structure imbedded in the sharp electron density gradients. The electron density is varying as much as $40 \%$ within the structures, and the more the variability, the higher $\Delta N_{e}{ }^{2}\left(k_{0}\right)$. (Note that $\Delta N_{e}{ }^{2}\left(k_{0}\right)=$ $\left.\left(\Delta N_{e} / N_{e}\right)^{2} \mathrm{H}^{-1} \times N_{e}^{2} \mathrm{~cm}^{-1}\right)$. Conversely, when there is significantly less structure in $N_{e}$, e.g., between 1 and 2 and 2 and $3, \Delta N_{e}{ }^{2}\left(k_{0}\right)$ is much lower. As pointed out by Thrane and Grandel [1981] and others, the efliciency of electron structuring driven by neutral turbulence is directly proportional to the electron density gradient scale length, $L=[1 / n(d n / d z)]^{-1}$. On the upper edge of this bite-out, $L$ is less than approximately $200 \mathrm{~m}$, which is very steep indeed. Further discussion of this structuring process is given by Kelley and Ulwick [this issue].

Turning to the STATE 1 data in Figure 3, there is also weak evidence for a large-scale depletion in the profile, but no deep bite-out. The radar echoes and the in situ structure measurements both show a first indication of activity near 86 $\mathrm{km}$ (shown in section 3.2.), the same altitude at which the bite-out occurred during STATE 3 and very near the minimum in the atmospheric temperature measured on June 15 , 1983. To first order, the radar echoes and the in situ turbulence maximize on the steepest part of the upward electron density gradient between 87.5 and $90 \mathrm{~km}$. The STATE 1 gradient is much weaker than the STATE 3 gradients, with $L \simeq 4$ $\mathrm{km}$.

In Figure 11 we compare the rocket ascent and descent results from STATE 1 . The rocket on descent at $88 \mathrm{~km}$ was about $25 \mathrm{~km}$ northwest of the ascent position at the same altitude. Clearly, the electron density is structured near the same altitude (within the uncertainties of the rocket trajectory), but the characteristics of the turbulence are quite different. This perhaps is not surprising, since the radar results indicate spatial variations of the structured regions (e.g., see 

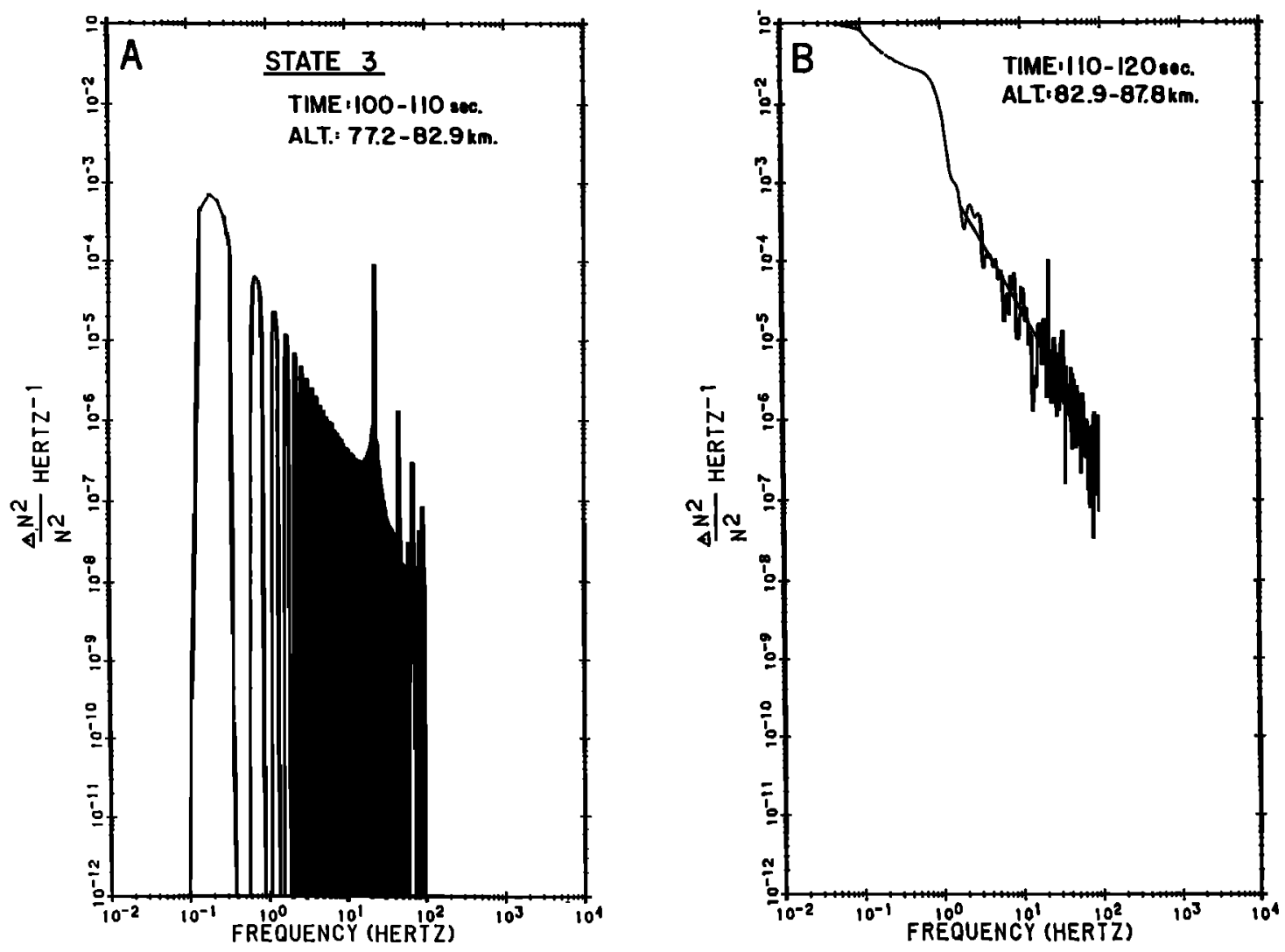

Fig. 8. Power spectral analysis of electron density fluctuations from the STATE 3 rocket: $(a) 100-110 \mathrm{~s}$ and $(b)$ 110$120 \mathrm{~s}$.

Figure 3). Note, however, that above the depletion in both profiles near $88 \mathrm{~km}$, the descent results show a deep bite-out more similar to the STATE 3 results, i.e., steep gradients, large electron density bite-out, and structure imbedded in the gradients. The descent data are complicated by a spin/coning effect near and after apogee, characteristic of very lightweight Super Arcas rocket payloads, making spectral analysis difficult.

An expanded zero-order electron density profile and the $\Delta N_{e}{ }^{2}\left(k_{0}\right)$ parameter discussed earlier are plotted for STATE 1 in Figure 12 for rocket ascent. This presentation seems to show a fine structure on the zero-order electron density gradient, which, in turn, organizes the fine-scale structure of the turbulence. For example, the relative minima in local electron density at $87.7,88.4,89.2$, and even at $89.8 \mathrm{~km}$, all show relative maxima in the turbulent power at small scales. This feature is discussed further by Kelley and Ulwick [this issue], who speculate that the large-scale wave process responsible for the turbulence in the neutral atmosphere above the mesopause has a vertical structure which organizes the local regions of intense small-scale (e.g., $3 \mathrm{~m}$ ) turbulence.

Turning now to a comparison of the spectral data in Figure 9 , both data sets show a change in spectral slope around 100 $\mathrm{Hz}$. The difference in slope is much more pronounced in STATE 1 than in STATE 3. The STATE 1 data appear much more like a classical passive scalar mixed by turbulence, both in spectral form and by visual inspection, than do the STATE 3 data. As discussed in more detail by Kelley and Ulwick [this issue], this may be the consequence of a significant contribution to the STATE 3 spectrum by the very steep edges on the electron density profile. Such an edge tends to introduce a $k^{-2}$ dependence in a power spectrum and could contribute to the steeper $k$ spectrum at small $k$.

If the two $\left(\Delta N_{e} / N_{e}\right)^{2}$ spectra are overlaid and the power levels made to match at $100 \mathrm{~Hz}$, the spectral shape is nearly identical for $f \geq 100 \mathrm{~Hz}$. This suggests that the process which leads to a steep spectrum, e.g., diffusive damping, is nearly identical for the turbulence-driven case (STATE 1) and edgesteepened plus turbulence-driven case (STATE 3).

Finally, at the frequency and wave number corresponding to 3-m waves, the STATE $3\left(\Delta N_{e} / N_{e}\right)^{2}$ power is roughly a factor 2 higher than the power detected during STATE 1 . This at first glance seems to be a paradox, since the radar scattering is some $16 \mathrm{~dB}$ stronger for STATE 1 . However, the radar scattering power is proportional to $\left(\Delta N_{e} / N_{e}\right) N_{e}{ }^{2}$, not just $\left(\Delta N_{e} / N_{e}\right)^{2}$, and $N_{e}{ }^{2}$ is roughly 64 times greater in the STATE 1 case. The net predicted increase in radar power is thus roughly a factor of 32 , which corresponds to $15 \mathrm{~dB}$. This relative comparison is very encouraging. In the next section a detailed quantitative calculation of the expected scattering power is made.

\subsection{Rocket and Radar Comparison}

In order to examine the relationship between the electron density fluctuations and the MST radar signal-to-noise ratio, the pulsed-radar equation for volume-filled scattering presented by Balsley and Gage [1980] can be expressed as

$$
\sigma=\frac{2 \pi c k_{B}\left(T_{s}+\alpha T_{C}\right)}{P_{T} A_{e} \alpha^{2} F_{i}}\left(\frac{r}{\Delta_{r}}\right)^{2} \frac{S}{N}
$$



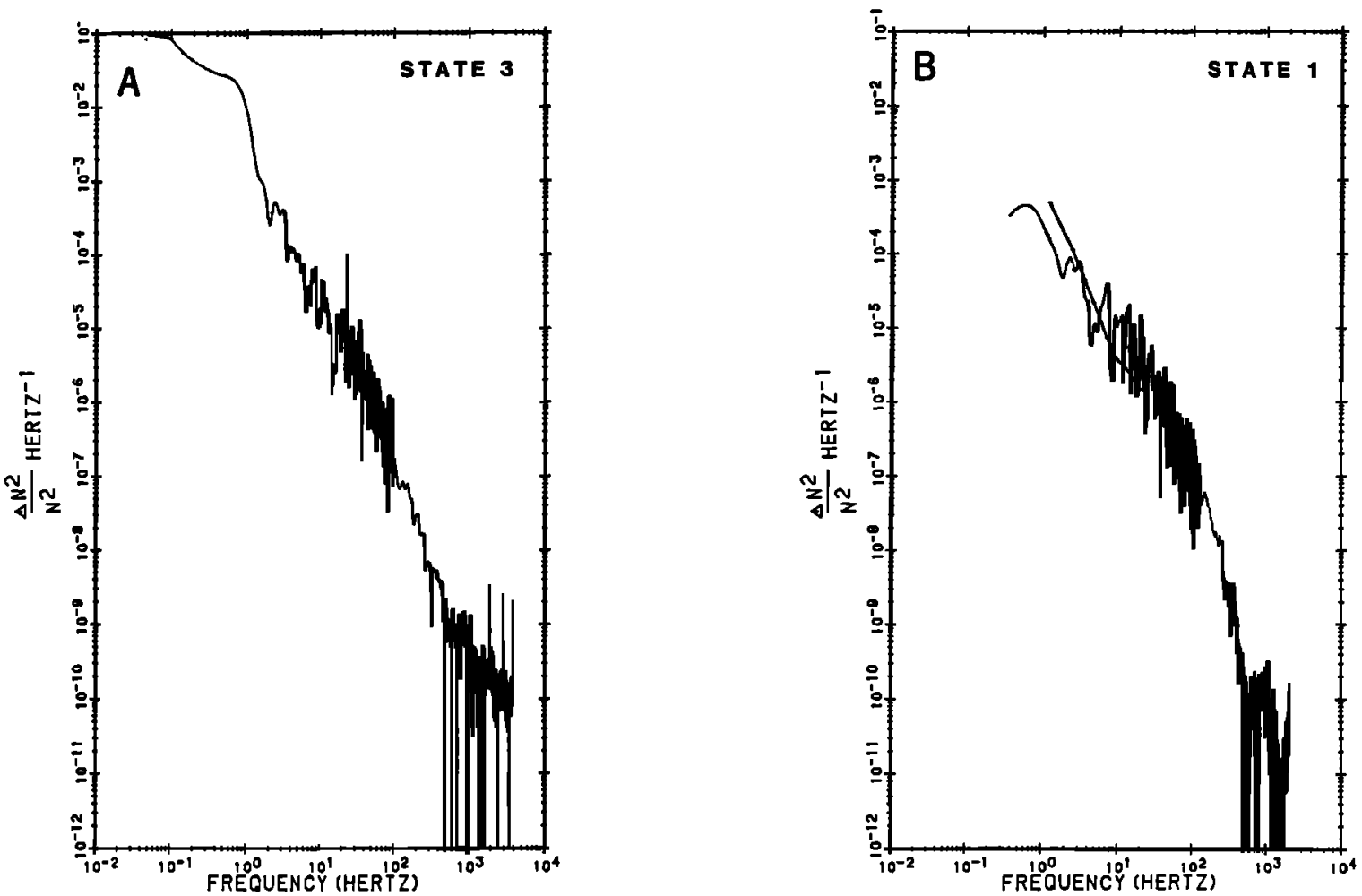

Fig. 9. (a) Average of 0.5-s power spectra from the STATE 3 rocket in the interval from 110 to $120 \mathrm{~s}$. (b) Similar data from the STATE 1 rocket, repeated here for comparison.

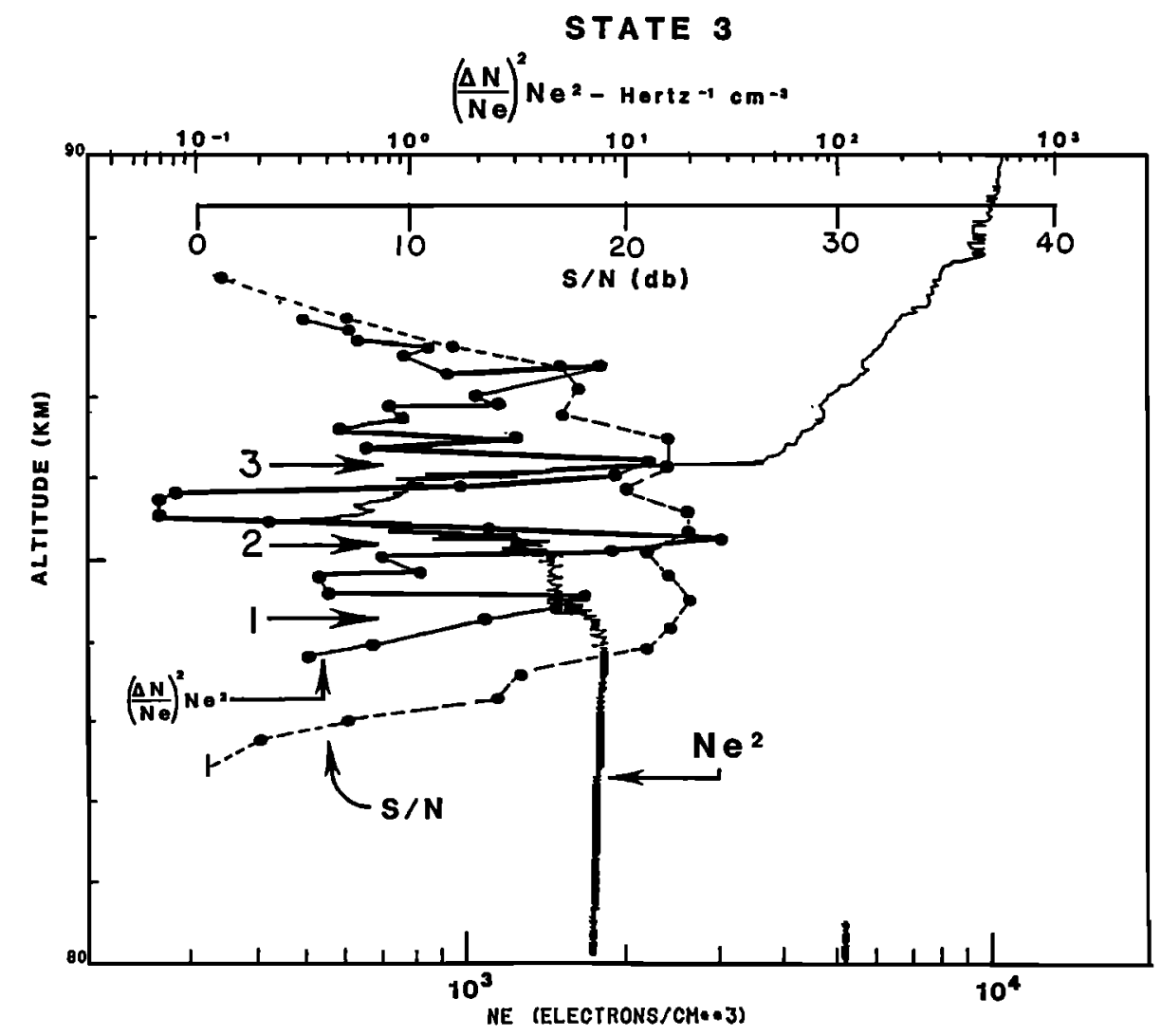

Fig. 10. High-resolution power spectra of electron density fluctuations, plotted along with the electron density profile for the STATE 3 results. 


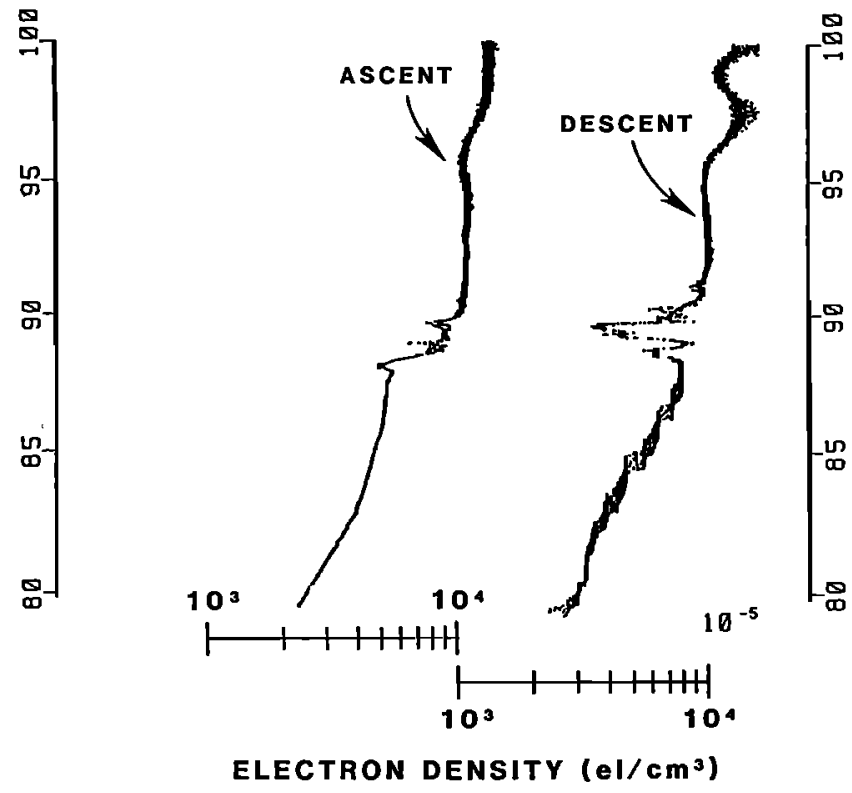

Fig. 11. Rocket ascent and descent electron density profiles from the de probe on STATE 1 rocket.

where $c$ is the velocity of light and $k_{B}$ is the Boltzmann's constant. The definitions and values of the Poker Flat radar parameters are given in Table 1.

Equation (1) reduces to

$$
\sigma=1.15 \times 10^{-17} \mathrm{~S} / \mathrm{N} \mathrm{m}^{-1}
$$

Royrvik and Smith [1984] derived the reflectivity in terms of

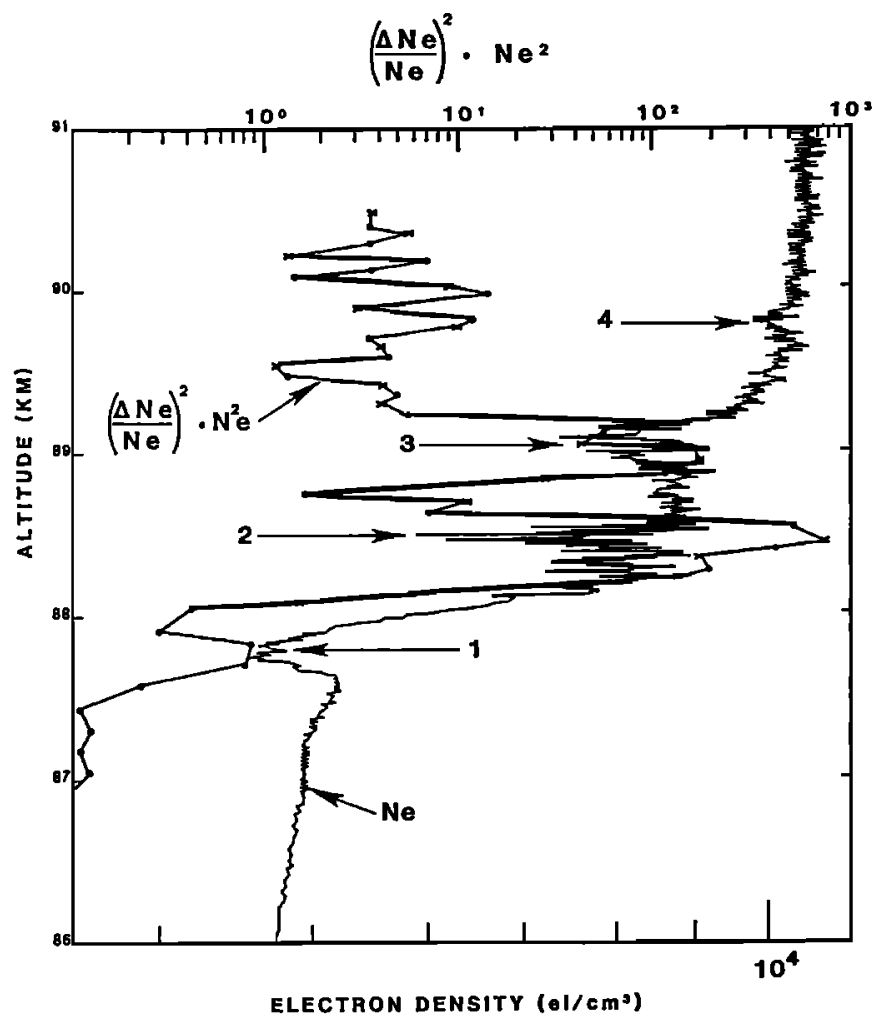

Fig. 12. Expanded zero-order electron density profile (dots) and $\mathrm{Ne}_{e}{ }^{2}$ parameter (crosses) (see text). Arrows indicate altitudes of relative minima in electron density and maxima in turbulent power at small scales.
TABLE 1. MST Radar Parameters

\begin{tabular}{lll}
\hline Symbol & \multicolumn{1}{c}{ Definition } & \multicolumn{1}{c}{ Value } \\
\hline$\sigma$ & radar volume reflectivity & $\ldots$ \\
$S / N$ & spectral total signal-to-total noise ratio & $\cdots$ \\
$r$ & range & $88.49 \times 10^{3} \mathrm{~m}$ \\
$\Delta r$ & range resolution & $300 \mathrm{~m}$ \\
$T_{s}$ & system noise temperature & $400^{\circ} \mathrm{K}$ \\
$T_{c}$ & cosmic noise temperature & $4000^{\circ} \mathrm{K}$ \\
$\alpha$ & resistive antenna losses & 0.65 \\
$A_{e}$ & effective antenna area & $3 \times 10^{4} \mathrm{~m}^{2}$ \\
$P_{T}$ & peak transmitted power & $1.46 \times 10^{6} \mathrm{~W}$ \\
$F_{i}$ & number of coherent integrations & 32 \\
\hline
\end{tabular}

the rocket irregularity spectrum, to obtain

$$
\sigma(k)=-n\left(\frac{\pi}{8}\right) k^{2} \frac{f_{p}^{4}}{4 f^{4}}\left[\frac{S_{n}(k)}{N_{e}^{2}}\right]
$$

where $n$ is the spectral index; $k, 2.1 \mathrm{rad} \mathrm{m}^{-1}, f_{p}$, the plasma frequency; $f$, the frequency of the probing wave; $S_{n}(k)$, the one-dimensional spectrum measured by the rocket (in meters per radian); and $N_{e}$, the electron density (in cubic meters). Equation (3) reduces to

$$
\sigma(k)=4.5 \times 10^{-28}(-n) N_{e}^{2}\left[\frac{S_{n}(k)}{N_{e}^{2}}\right]
$$

combining (4) and (2)

$$
\mathrm{S} / \mathrm{N}=3.91 \times 10^{-11}(-n) N_{e}^{2}\left(\frac{S_{n}(k)}{N_{e}^{2}}\right)
$$

Finally, in order to compute $\mathrm{S} / \mathrm{N}$ using the existing data analysis, which is expressed in units of $\left(\Delta N_{e} / N_{e}\right)^{2} \mathrm{~Hz}^{-1},(5)$ is rewritten as

$$
\mathrm{S} / \mathrm{N}=\frac{3.91 \times 10^{-11}(-n) N_{e}{ }^{2} V_{R}}{2 \pi}\left(\frac{\Delta N_{e}}{N_{e}}\right)^{2}
$$

where $V_{R}$ is the rocket velocity in meters per second. These expressions are valid provided the electron density fluctuations are isotropic and have a negative power law scale size distribution.

The calculated $\mathrm{S} / \mathrm{N}$ from (6) at 0.5 -s intervals, corresponding to a height resolution of about $250 \mathrm{~m}$ (compared with the radar 300-m height resolution) is shown in Figure $13 a$ for STATE 1, with the radar $\mathbf{S} / \mathrm{N}$ measurement superimposed. The agreement in general is good, although the calculated values are noticeably higher at the peak $S / N$. The $S / N$ from the rocket data is shown as $0 \mathrm{~dB}$ from about 84 to $86.4 \mathrm{~km}$, because a spectral index could not be resolved. Above $90 \mathrm{~km}$, no $\mathrm{S} / \mathrm{N}$ could be calculated, since, as mentioned, the spectra above this altitude all have "white noise" characteristics more typical of plasma processes which are not isotropic and which do not scatter the radar signals at such high elevation angles ( $k$ must be perpendicular to $B$ to receive scatter from such plasma waves).

In Figure $13 b$ the signal-to-noise calculated using 0.5 -s time series (250-m height resolution) spectra from STATE 3 rocket probe measurements shows much more structure than the radar $\mathrm{S} / \mathrm{N}$. The radar S/N for STATE 3, however, does show indications of structure and certainly shows more than the STATE 1 radar measurements. If a time series over 2-s intervals is used, considerable smoothing results, as shown in Figure $10 b$. 

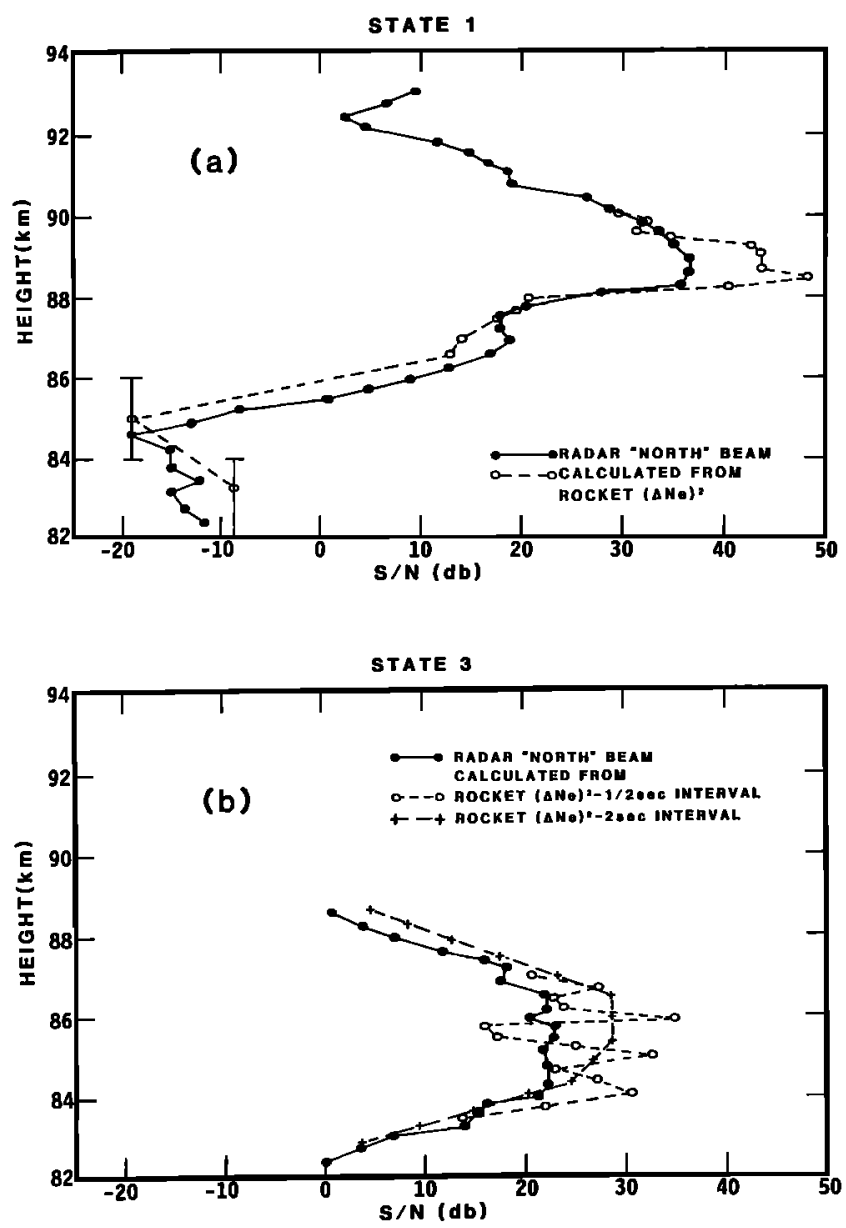

Fig. 13. MST radar echo power (S/N) measured by the north beam and calculated from the high-resolution electron density power fluctuations measured by the rocket probes: (a) STATE 1 results and (b) STATE 3 results.

\section{Summary}

The data from the two Super Arcas rocket electron density probes during the STATE campaign, coupled with the MST radar data, have given very new and interesting results on the cold summer polar mesosphere, as contained in this paper and the companion paper by Kelley and Ulwick [this issue]. We summarize the main results from this paper as follows:

\subsection{STATE I}

1. The altitude profile of the MST radar echo power is in excellent agreement with the structure in the electron density observed in the rocket data, even in regions of weak radar signal. The structured region is mostly on or above the steep gradient in electron density.

2. The power spectra characteristics are exactly as one would predict for a passive scalar mixed by a turbulent neutral fluid, although an anomously high Schmidt number is required [see Kelley and Ulwick, this issue].

3. The calculated signal-to-noise ratio from the onedimensional spectra measured by the rocket is in good agreement with the MST radar $\mathrm{S} / \mathrm{N}$ profile.

4. The structured region shows distinctive spatial variations.

\subsection{STATE 3}

1. The intense radar backscatter signal is centered on a deep "bite-out" in the electron density profile. The structured region is mostly on or below the sharp gradient in electron density.

2. For frequencies less than $100 \mathrm{~Hz}$, the spectral slope is influenced by the steep edges on the electron density profile.

3. The characteristics of the power spectra for frequencies greater than $100 \mathrm{~Hz}$ are identical to STATE 1, suggesting that the process leading to a steeper spectrum is nearly identical for the turbulence-driven case (STATE 1) and edge-steepened plus turbulence-driven case (STATE 3).

4. The radar $\mathrm{S} / \mathrm{N}$ measurements appear to smooth the more structural $\mathbf{S} / \mathbf{N}$ profile from the electron density measurements.

Acknowledgments. The authors acknowledge the contributions of the personnel of Center for Space Engineering at Utah State University, the Air Force Geophysics Laboratory, and the Geophysical Institute of the University of Alaska, who were instrumental in the sources of the rocket program. The Directorate of Chemical and Atmospheric Sciences, Air Force Office of Scientific Research supported the data analysis under grant AFOSR-85-0163.

\section{REFERENCES}

Baker, K. D., J. LaBelle, R. F. Pfaff, L. C. Howlett, N. B. Rao, J. C. Ulwick and $\mathrm{M}$. C. Kelley, Absolute electron density measurements in the equatorial ionosphere, J. Atmos. Terr. Phys., 47, 781, 1985.

Balsley, B. B. and K. S. Gage, The MST radar technique: Potential for middle atmospheric studies, Pure Appl. Geophys., 118, 452, 1980.

Balsley, B. B., W. L. Ecklund, D. A. Carter, and P. E. Johnson, The MST radar at Poker Flat, Alaska, Radıo Sci, I5, 213, 1980.

Blackman, B. B., and J. W. Tukey, The Measurement of Power Spectra, Dover, New York, 1958.

Driscoll, R. J., and P. Kennedy, A model for the spectrum of passive scalars in an isotropic turbulent field, Phys. Fluids, 28(1), 72-1985.

Fejer, B. G., and M. C. Kelley, Ionospheric irregularities, Rev. Geophys., $18,401,1980$.

Fritts, D. C., S. A. Smith, B. B. Balsley and C. R. Philbrick, Evidence of gravity wave saturation and local turbulence production in the summer mesosphere and lower thermosphere during the STATE experiment, J. Geophys. Res., this issue.

Johannessen, A., and D. Krankowsky, Positive-ion composition measurement in the upper mesosphere and lower thermosphere at a high latitude during summer, J. Geophys. Res., 77, 2888, 1972.

Kelley, M. C., and J. C. Ulwick, Large- and small-scale organization of electrons in the high-latitude mesosphere: Implications of the STATE data, J. Geophys. Res., this issue.

Philbrick, C. R., D. P. Sipler, B. B. Balsley, and J. C. Ulwick, The STATE experıment-Mesospheric dynamics, Adv. Space Res., 4, 129-132, 1984.

Royrvik, O., and L. G. Smith, Comparison of mesospheric VHF radar echoes and rocket probe electron concentration measurements, J. Geophys. Res., 89, 9014, 1984.

Tartarskii, V. I., Wave Propagation in a Turbulent Medium, McGrawHill, New York, 1961.

Thrane, E. V., and B. Grandel, Observations of fine scale structure in the mesosphere and lower thermosphere, J. Atmos. Terr. Phys., 43, $179,1981$.

Watkins, B. J., C. R. Philbrick, and B. B. Balsley, Turbulence energy dissipation rates and inner scale sizes from rocket and radar data, J. Geophys. Res., this issue.

K. D. Baker and J. C. Ulwick, Department of Electrical Engineering, Utah State University, Logan, UT 84322.

B. B. Balsley and W. L. Ecklund, Aeronomy Laboratory, National Oceanic and Atmospheric Administration, 325 Broadway, Boulder, CO 80303 .

M. C. Kelley, School of Electrical Engineering, Cornell University, Phillips Hall, Ithaca, NY 14853. 